\title{
Influence of Stress Re-distribution on Hydrogen-induced Fatigue Crack Propagation
}

\author{
Daisuke SASAKI, ${ }^{1) *}$ Motomichi KOYAMA ${ }^{2)}$ and Hiroshi NOGUCHI ${ }^{21}$ \\ 1) Department of Materials System Engineering, National Institute of Technology, Kurume College, 1-1-1 Komorino, Kurume, \\ Fukuoka, 830-8555 Japan. \\ 2) Department of Mechanical Engineering, Kyushu University, 744 Moto-oka, Nishi-ku, Fukuoka, Japan.
}

(Received on January 9, 2019; accepted on April 12, 2019; originally published in Tetsu-to-Hagané, Vol. 104, 2018, No. 1, pp. 46-53; J-STAGE Advance published date: June 25, 2019)

\begin{abstract}
In order to clarify influence of stress re-distribution effect on hydrogen-induced fatigue crack propagation, we investigated fatigue crack propagation rates and brittle-like fracture ratio. The experiments were conducted in nitrogen and hydrogen gas atmosphere with ferrite-pearlite steels having different pearlite ratio, respectively. The crack propagation rates and the brittle-like fracture ratio decreased as pearlite ratio increased. To explain the changes of crack propagation rates and fracture ratio, we proposed that the stress re-distribution effect causing stress and strain relaxation at a crack tip contributes to suppression of the hydrogen-induced fatigue crack propagation. As a verification, finite element methods were operated with models having different width of the hard phase and different distance between a crack tip and a hard phase in plane stress and strain conditions, respectively. The finite element method analysis showed that stress re-distribution effect was smaller in plane strain condition than that in plane stress condition, indicating that a large hardness difference is crucial in plane stress condition to suppress the hydrogen-induced fatigue crack propagation.
\end{abstract}

KEY WORDS: stress re-distribution; ferrite; pearlite; hydrogen embrittlement; fatigue; pre-cracked specimen; fatigue crack growth.

\section{Introduction}

The government has been promoting the use of hydrogen energy because it is a potential solution to the prevailing energy problem. In this regard, hydrogen vehicles, fuel cell vehicles, and hydrogen infrastructures have been developed. However, hydrogen degrades the mechanical properties of steel. $^{1-6)}$ Therefore, it is essential to find hydrogen-resistant high-strength alloys and develop strategies for their application in this field. ${ }^{7,8)}$ Some important properties of the steel used in high-pressure hydrogen environments are allowable stress, reduction ratio, and strength reduction ratio, etc. ${ }^{7)}$ In addition to these tensile properties, some researchers have recently reported fatigue fracture behavior under a hydrogen atmosphere. $^{9-12)}$

One of the factors accelerating fatigue fracture under a hydrogen atmosphere is hydrogen enhanced-localized plasticity (HELP). ${ }^{13,14)}$ The HELP effect increases the crack propagation rate by a factor of 10 , and the fatigue life is shortened. ${ }^{15-17)}$ To understand the HELP-assisted fatigue crack growth, brittle-like striations in the fracture surface are important. The brittle-like striations have a larger striation spacing and smaller roughness than those of the striations formed in the absence of the HELP effect. These

* Corresponding author: E-mail: d-sasaki@kurume-nct.ac.jp DOI: https://doi.org/10.2355/isijinternational.ISIJINT-2019-012 unique striations have been observed on the intragranular crack surfaces of $\mathrm{Fe}-\mathrm{Si}$ single crystals ${ }^{18)}$ and commercial polycrystalline ferritic steel. ${ }^{19)}$ More specifically, the fracture surface has a cleavage-like feature, but the crack propagation path does not correspond to specific cleavage planes. ${ }^{20)}$ To explain this crack propagation behavior, a local ductile crack propagation mechanism ${ }^{19)}$ has been proposed based on hydrogen-induced microvoid formation and coalescence. ${ }^{21)}$ In this model, the crack opens with slip at the crack tip. The crack tip deformation is localized and assisted by the localized hydrogen concentration. Then, the strain localization at the crack tip causes void formation and subsequent coalescence, resulting in stable crack propagation during the loading process. ${ }^{22}$ )

As mentioned above, the localized plasticity at the crack tip accelerates the fatigue crack growth, but the stress redistribution associated with the plastic constraint decelerates the fatigue crack propagation. ${ }^{23,24)}$ The stress redistribution is a result of the accommodation of the strain incompatibility around the interface of the two phases with different material constants. The microstructural stress redistribution in high-strength steels, such as dual-phase and transformation-induced plasticity steels, is an origin of their high ductility and strength. However, there have been no studies focused on stress redistribution for fatigue crack propagation under a hydrogen atmosphere.

In this study, we investigated the influence of stress redis- 
tribution on hydrogen-assisted fatigue crack propagation in dual-phase microstructure comprising ferrite and pearlite. Understanding the influence of stress redistribution on hydrogen-assisted fatigue crack propagation will allow us to develop a microstructure with high hydrogen embrittlement resistance and improved hydrogen-related infrastructure. Our study focused on the following:

1.) The effect of the hard phase on the fatigue crack growth rate (FCGR) and behavior under hydrogen and nitrogen atmospheres.

2.) The effect of the hard phase on the formation of brittle-like striations.

3.) The effect of the hard phase on stress redistribution of surface and internal cracks.

\section{Experimental Method}

Two types of ferrite-pearlite steels (Material A, Material B) with different pearlite fractions were used. Table 1 shows the chemical composition of both materials. The steel bars had diameters of $22 \mathrm{~mm}$ and were heat-treated at 950 $\mathrm{K}$ for $1 \mathrm{~h}$ and then furnace cooled to room temperature. Figures 1(a) and 1(b) show the microstructures after the heat treatment. The initial structures of both steels comprised ferrite-pearlite, and the average crystal grain sizes of materials A and B were about $20 \mu \mathrm{m}$ and $24 \mu \mathrm{m}$, respectively. Hereafter, the ferrite and pearlite are called the soft and hard phases, respectively. The hard phase fractions were $20.8 \%$ in material $\mathrm{A}$ and $46.2 \%$ in material $\mathrm{B}$. After machining the specimens to the shapes shown in Fig. 2(a), the surfaces of the specimens were polished using emery paper \#2000 and then buffed using colloidal silica with a particle diameter of $50 \mathrm{~nm}$. After cleaning, the surfaces of the specimens were etched with $3 \%$ nital to elucidate the relationship between the crack propagation behaviors of the soft and hard phases. Two drill holes were introduced into the specimen surface to simulate micro-defects. The diameter $d$ and depth $h$ of a drill hole were both $100 \mu \mathrm{m}$. The two drill holes were connected, as shown in Fig. 2(b) so that they were aligned perpendicularly to the longitudinal direction. The distance to both ends of the two drill holes was from 230 to $240 \mu \mathrm{m}$ on the surface.

A fully reversed bending fatigue test using displacement control was performed. Figure 2(c) shows the bending direction. The test waveform was a triangular wave with a frequency of $6 \mathrm{~Hz}$. In situ observations were conducted using an optical microscope. The crack length was defined as the projected length including the diameter of the two drilled holes in the y-direction, as shown in Fig. 2(d). The test environment was a pure hydrogen gas atmosphere at $313 \mathrm{~K}$ with an absolute pressure of $0.18 \mathrm{MPa}$ and a purity of $99.9999 \%$. To clarify changes in the crack propagation behavior due to hydrogen, we conducted the test under the same conditions in a pure nitrogen gas environment with a purity of $99.9999 \%$. The total strain range of the fatigue test was set to $\Delta \varepsilon_{\mathrm{t}}=0.70 \%$. The strain width was measured by a strain gage installed at the center of the rear surface of the specimen. Before the fatigue test, the specimen was held for $1 \mathrm{~h}$ in the hydrogen environment at $313 \mathrm{~K}$ and $0.18 \mathrm{MPa}$ to form a uniform hydrogen solid solution and specimen temperature. Furthermore, after observing fatigue
Table 1. Chemical compositions of the steels used (mass $\%$ ).

\begin{tabular}{ccccccc}
\hline Material & C & Si & Mn & P & S & N \\
\hline A & 0.21 & 0.21 & 0.53 & 0.012 & 0.016 & 0.0089 \\
B & 0.31 & 0.29 & 0.77 & 0.011 & 0.013 & 0.0048 \\
\hline
\end{tabular}

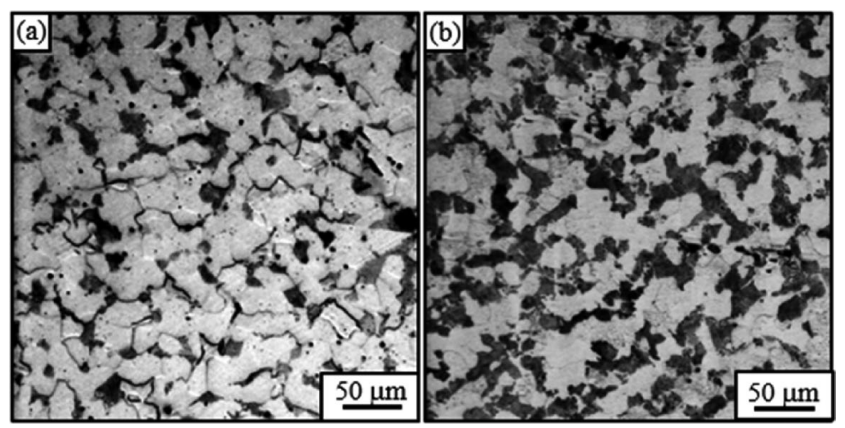

Fig. 1. Microstructures of (a) material A and (b) material B respectively.

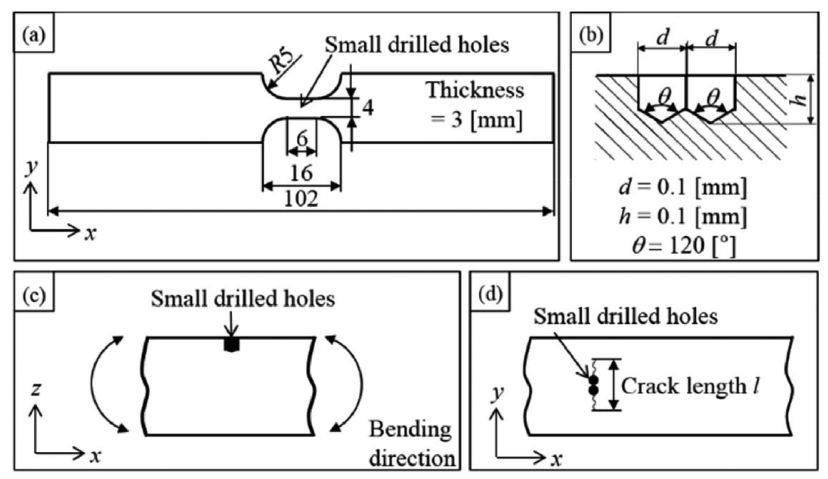

Fig. 2. Specimen configuration. (a) Overall view of the specimen. (b) The shape of the drill holes. (c) Bending direction. (d) The definition of the crack length.

crack propagation behavior, the specimen was broken using low-temperature embrittlement by immersing it in liquid nitrogen, and the fracture surface was observed by scanning electron microscopy (SEM). The brittle fracture surface fraction was calculated with binarization of fractrographs using ImageJ. To obtain the brittle fracture surface fraction in the soft phase, we divided the brittle fracture surface fraction by the area fraction of the soft phase.

\section{Experimental Results and Discussion}

\subsection{Crack Propagation Rate}

Figure 3 shows the relationship between the number of cycles and the crack length on materials A and B in hydrogen and nitrogen gas environments. Here, we assumed that the shape effect of the drill hole did not affect the fatigue crack propagation when the total crack length was over 750 $\mu \mathrm{m}$, based on Saint-Venent's principle. The crack length included the drill holes. To discuss stable fatigue crack propagation, the horizontal axis is the number of cycles from the crack length of $750 \mu \mathrm{m}$. Therefore, we focused on crack length range from 750 to $1400 \mu \mathrm{m}$. Under nitrogen gas environment, the average FCGRs of both materials A and $B$ were $0.12 \mu \mathrm{m} /$ cycle when the crack lengths were 


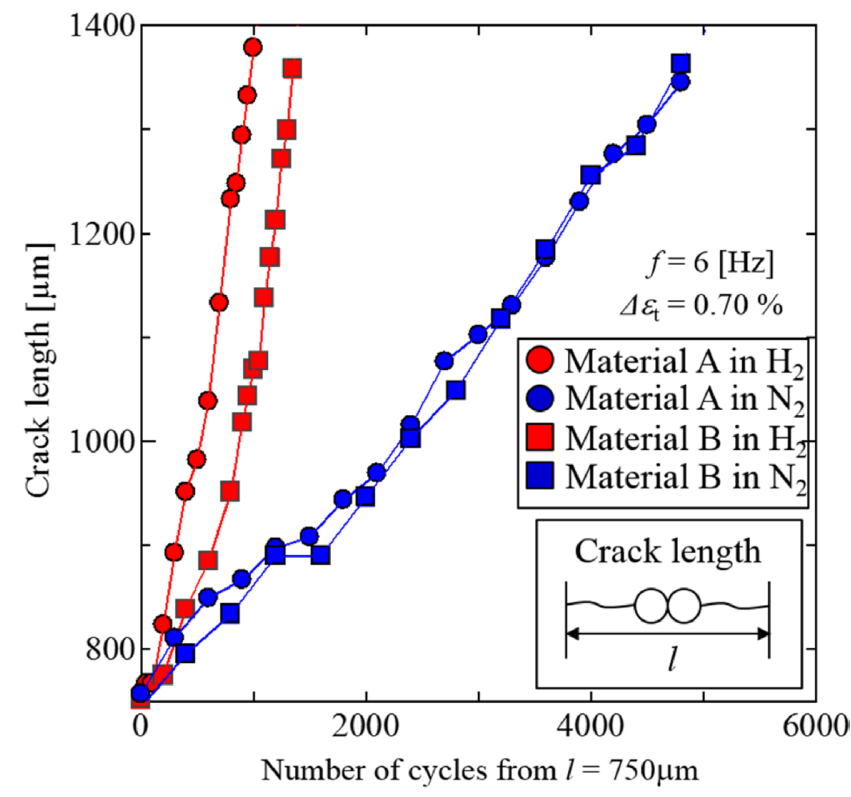

Fig. 3. The relationship between number of cycles from $750 \mu \mathrm{m}$ and crack length. Round and Square marks indicate the data of material A and B, respectively. Blue and red dates mean the data in the nitrogen and the hydrogen gas atmosphere, respectively. (Online version in color.)

between 750 and $1400 \mu \mathrm{m}$. The average FCGR of S10C ferrite-pearlite steel under similar test conditions was about $0.12 \mu \mathrm{m} /$ cycle for crack lengths between 800 and 2000 $\mu \mathrm{m} .{ }^{16)}$ The experimental results for $\mathrm{S} 10 \mathrm{C}$, material $\mathrm{A}$, and material B are consistent, which can be explained as follows. The Manson-Coffin law can be used to predict the low-cycle fatigue life of strain control test, indicating that plastic strain dominates the low-cycle fatigue crack propagation. In Section 3.4, we discuss the effect of crack tip plastic strain and hard phase distribution.

In the hydrogen gas environment, the FCGRs of materials $\mathrm{A}$ and $\mathrm{B}$ were 0.63 and $0.45 \mu \mathrm{m} /$ cycle, respectively. Compared to the FCGR in the nitrogen gas environment, the FCGRs were 5.3 and 3.8 times greater for materials A and $\mathrm{B}$, respectively.

\subsection{Crack Propagation Behavior}

Figure 4 shows the results for surface cracks with material $\mathrm{A}$ in the hydrogen and nitrogen gas environments. First, we discuss surface cracks in the hydrogen gas environment. In Fig. 4, arrows indicate the crack tip at each cycle number after $750 \mu \mathrm{m}$. Cracks propagated from right to left in Fig. 4. The white dotted lines in Fig. 4 are the crack propagation paths. In Figs. 4(b) and 4(c), the red region indicates the hard phase, and the other region indicates the soft phase.

Figure 4(a) shows the result for a crack length of 750 to $1400 \mu \mathrm{m}$ in the hydrogen gas atmosphere. As shown in Fig. 4(a), the crack observation in the hydrogen gas environment shows following features. 1) Slip bands occurred within the soft phase at the beginning of the fatigue test. 2) Fatigue cracks propagate through the soft phase or grain boundary, hard phase. 3) When progressing in the soft phase, the crack propagates along the existing slip bands. 4) The FCGR in the hard phase or the vicinity of the hard phase is smaller than that of the soft phase.

More specifically, as shown in Fig. 4(b), the one-sided
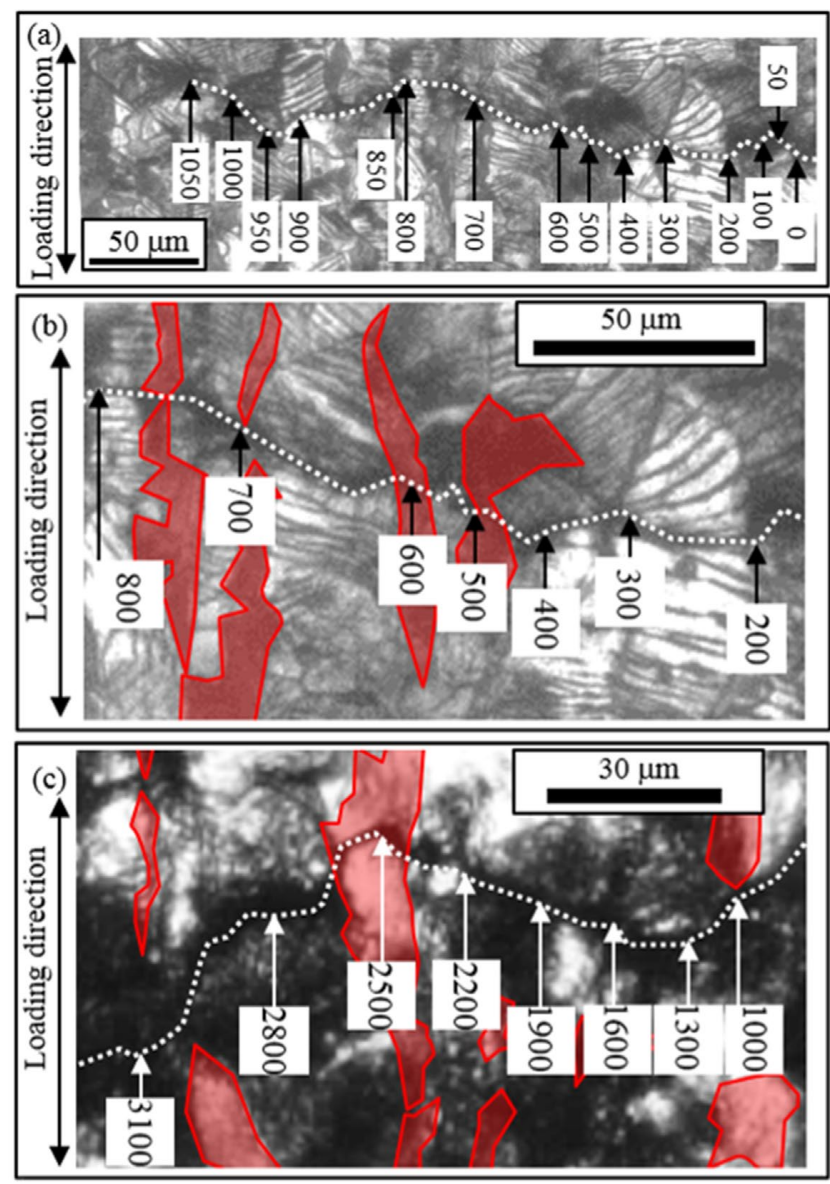

Fig. 4. Surface crack observation of material A. (a) Crack growth path of the material A in the hydrogen gas atmosphere. (b) is an enlarged photo of the area from 200 cycles to 800 cycles. (c) Crack growth path of the material A in the nitrogen gas atmosphere. In Figs. 4(b) and 4(c), the red area is the hard phase. (Online version in color.)

FCGR inside the hard phase was $0.14 \mu \mathrm{m} /$ cycle when the number of cycles was between 400 and 600 cycles. From 600 to 700 cycles, where the crack propagates in the soft phase, the one-sided FCGR was $0.38 \mu \mathrm{m} /$ cycle. Also, in material B, the FCGR in the soft phase was faster than that in hard phase. It was shown that the hard phase prevents fatigue crack propagation in the hydrogen gas environment.

Figure 4(c) shows the result in crack length ranging from 810 to $1100 \mu \mathrm{m}$ in the nitrogen gas environment. Slip bands appeared in the soft phase grains at the beginning of the fatigue test in both materials A and B. However, clear slip lines like the one seen in Fig. 4(a) were not observed in the nitrogen gas environment. The crack growth in the nitrogen gas environment also showed similar behavior to the results 1), 2) and 3) observed in the hydrogen gas environment. On the other hand, the FCGR did not significantly decrease near the hard phase, indicating that the resistance effect of the hard phase was smaller than that in the hydrogen gas environment. Specifically, the partial FCGR from 1000 to 2200 cycles was $0.04 \mu \mathrm{m} /$ cycle in the soft phase. In the pathway including the hard phase, the one-sided FCGR from 2200 to 2800 cycles was $0.0565 \mu \mathrm{m} /$ cycle. When the crack penetrated the hard phase, the one-sided FCGR from 2800 to 3100 cycles was $0.0695 \mu \mathrm{m} /$ cycle in the soft phase. These results show that the crack propagation resistance in the hard phase was small in the nitrogen gas environment. 
These results show that the FCGR significantly decreased inside or near the hard phase only in the hydrogen gas environment. In other words, the FCGR in the soft phase dominated the fatigue life in the hydrogen gas atmosphere.

\subsection{Verification of Stress Re-distribution}

We observed the fatigue fracture surfaces using SEM. Figure 5 shows the fracture surface of material A in the hydrogen gas environment. Drill holes are visible above the center of the image. The two black-dot lines indicate the imaginary crack front at crack lengths of 750 and 1400 $\mu \mathrm{m}$, respectively. In the fracture surface, a radial pattern expanded from the drill holes, and brittle-like striations were confirmed.

Figure 6 shows an enlarged view of the fracture surface $550 \mu \mathrm{m}$ from the center of the specimen surface in the hydrogen gas environment. Brittle-like striations ${ }^{15,20)}$ with stripe patterns appeared, as indicated by red arrows in Fig.

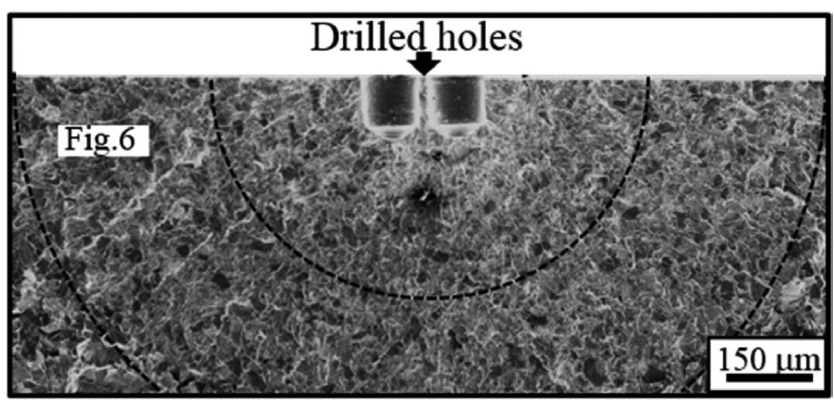

Fig. 5. The fracture surface of material B after the fatigue test in the hydrogen gas atmosphere.

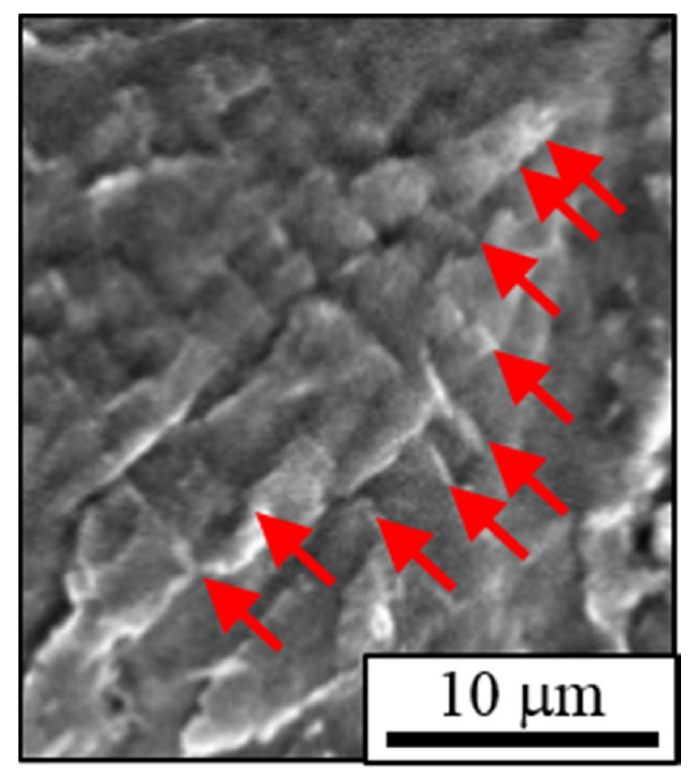

Fig. 6. Fracture surfaces of material B. (a) In the nitrogen gas atmosphere. (b) In the hydrogen gas atmosphere. (Online version in color.)

Table 2. Fracture surface fraction and soft phase ratio.

\begin{tabular}{cccc}
\hline Material & $S B[\%]$ & $S B F[\%]$ & Soft phase ratio [\%] \\
\hline A & 66 & 83 & 79.2 \\
B & 34 & 63 & 53.8 \\
\hline
\end{tabular}

6. In material $\mathrm{A}$, the brittle-like striation spacing was 2.57 $\mu \mathrm{m}$. In material $\mathrm{B}$, the brittle-like striation spacing was 1.59 $\mu \mathrm{m}$ on the fracture surface at the position $570 \mu \mathrm{m}$ far from the center of the specimen surface. The brittle-like striation spacing corresponds to the local FCGR in the soft phase. ${ }^{19)}$ The brittle-like striation width decreased with increased hard phase fraction, indicating that the rise in the hard phase fraction decreases the hydrogen-promoted FCGR.

Here, we assumed that the brittle-like striation formed in the soft phase. To discuss the influence of the hard phase fraction on the crack propagation in the soft phase, we defined the brittle-like fracture fraction, $S_{\mathrm{BF}}$, in the soft phase. $S_{\mathrm{BF}}$ was obtained by dividing the brittle-like fracture fraction $S_{\mathrm{B}}$ by fracture fraction of the soft phase. Table 2 shows the brittle-like fracture rate $S_{\mathrm{B}}$ in the entire fracture surface, the brittle-like fracture rate $S_{\mathrm{BF}}$ in the soft phase, and the soft phase fraction. As shown in Table 2, the brittlelike fracture rates $S_{\mathrm{B}}$ were $66 \%$ and $34 \%$ in materials A and $\mathrm{B}$, respectively. The brittle-like fracture rates $S_{\mathrm{BF}}$ in the soft phase were $83 \%$ and $63 \%$ in materials $\mathrm{A}$ and $\mathrm{B}$, respectively. As the hard phase fraction increased, the brittle-like fracture rates $S_{\mathrm{BF}}$ decreased. These results indicate that as the hard phase increased, the hydrogen-promoted crack propagation causing brittle-like fracture decreased. In summary: 1) the crack propagation rate in the soft phase decreased with the increase of the hard phase fraction and 2) the brittle-like fracture rate in the soft phase decreased as the hard phase fraction increased, showing that the increase of the hard phase fraction suppressed hydrogen-accelerated crack propagation. More specifically, these results indicate that the hard phase relaxed strain localization and hydrogen localization at a crack tip.

\subsection{Stress Redistribution on Surface Crack}

In this section, we clarify the influence of the stress redistribution by the hard phase on the surface crack stress field and plastic strain based on Finite Element Method (FEM) analysis. This discussion takes no account of a difference in local hydrogen content due to microstructure. Assuming that the hard phase does not break, we performed FEM analysis using the commercial software Marc 2013. Figure 7 shows the analytical model. In the FEM analysis, elements with material properties of the soft phase occupied most of the simulation domains. As shown in Figs. 7(c), 7(d), and 7(e), the hard phase is oriented parallel to the forced displacement direction near a crack tip in a layered fashion. In the model of material A, the hard phase thickness was set to $10 \mu \mathrm{m}$, and the soft phase/hard phase interface was configured to be located $30 \mu \mathrm{m}$ from the crack tip. Henceforth, this model is referred to as model 1. The material properties of the soft and hard phases were as follows: Young's modulus of 200 $\mathrm{GPa}$, Poisson's ratio of 0.3 , and work hardening coefficient of 0.2. The initial yield strength of pure pearlite ranged from 300 to $760 \mathrm{MPa}^{25,26)}$ As the pearlite fraction decreased, so did the initial yield strength. ${ }^{27)}$ In this study, the elements simulating the soft phase had initial yield strengths of 250 $\mathrm{MPa}$, and the elements simulating the hard phase had initial yield strengths of $500 \mathrm{MPa}$.

To discuss the influence of 1) the hard phase thickness and 2) the soft phase interval on the stress field and plastic strain at the crack tip, we used two other models. In model 


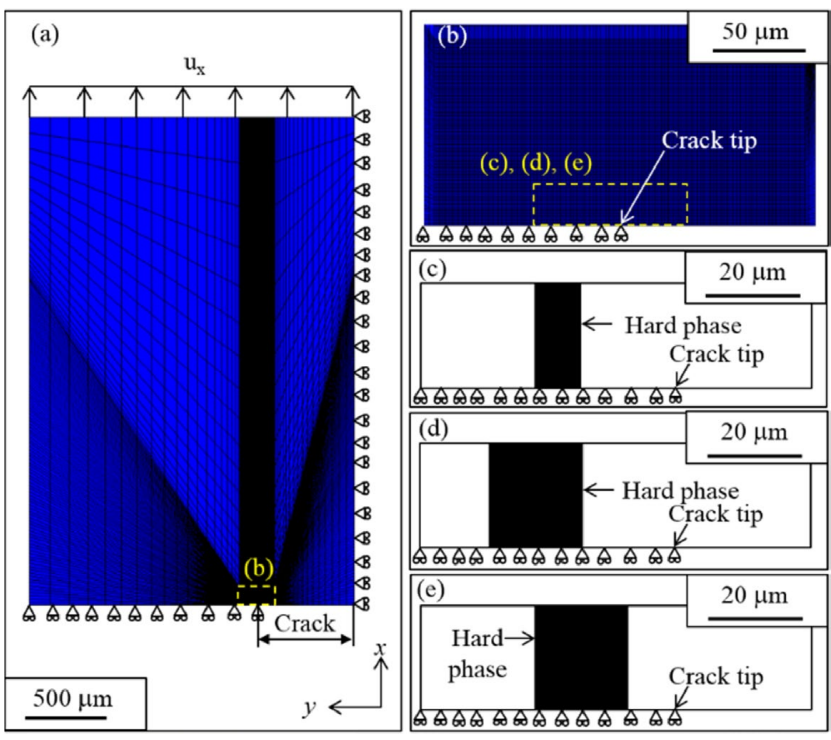

Fig. 7. FEM analysis model. (a) Overall view of the analysis model. (b) is an enlarged figure in Fig. 7(a). Figures 7(c), 7(d) and 7(e) are model 1, 2 and 3, respectively. (Online version in color.)

2 , the hard phase thickness was $20 \mu \mathrm{m}$. In model 3, the hard phase thickness was $20 \mu \mathrm{m}$ and the soft/hard phase interface was located $10 \mu \mathrm{m}$ from the crack tip.

The model shown in Fig. 7 is a two-dimensional plane model with a length of $3.00 \mathrm{~mm}$ in the $x$-axis direction (the loading direction) and a width of $1.00 \mathrm{~mm}$ along the $y$-axis direction. To examine the influence of the stress redistribution on the stress field and plastic strain at a surface crack tip, a plane stress state was used. To simulate experimental conditions with a total strain width of $\Delta \varepsilon_{\mathrm{t}}=0.70 \%$, the loading method included a $0.0105 \mathrm{~mm}$ forced displacement along the $x$-axis direction at the top of the model.

All the models simulated crack propagation up to a total length of $1200 \mu \mathrm{m}$ assuming symmetry in the $x$ and $y$ planes. Since the models represented a quarter of a specimen, the crack lengths were $600 \mu \mathrm{m}$. The $200 \mu \mathrm{m}$ region into front and rear of the crack front is 200 divided. In all the models, the number of elements and nodes were 29161 and 28800 , respectively. Four-node primary elements were used. Two hundred time-steps were used in all the simulations.

Frist, we discuss the influence of the hard phase on the equivalent plastic strain distribution at the crack tip. Figure $\mathbf{8}$ shows the results of the simulation. Using the hydrogeninduced fatigue crack propagation model, ${ }^{19}$ the equivalent plastic strain at the crack tip was related to microvoid formation and the crack propagation in the FEM analysis. As shown in Fig. 8, high plastic strain appeared at the crack tip in all models. The strain distribution about $5 \mathrm{~mm}$ from the crack tip did not significantly change. The plastic strains at the crack tip were $1.69,1.66$, and 1.62 in models 1,2 , and 3 , respectively. The difference in plastic strains between these models was $4.14 \%$ at the maximum. The FCGR in the nitrogen gas environment were the same for materials A and B. Thus, there was only a slight difference between the strains at the crack tip in FEM analysis.

Second, we discuss the influence of the hard phase on the hydrostatic stress. Figure 9 shows the results of the

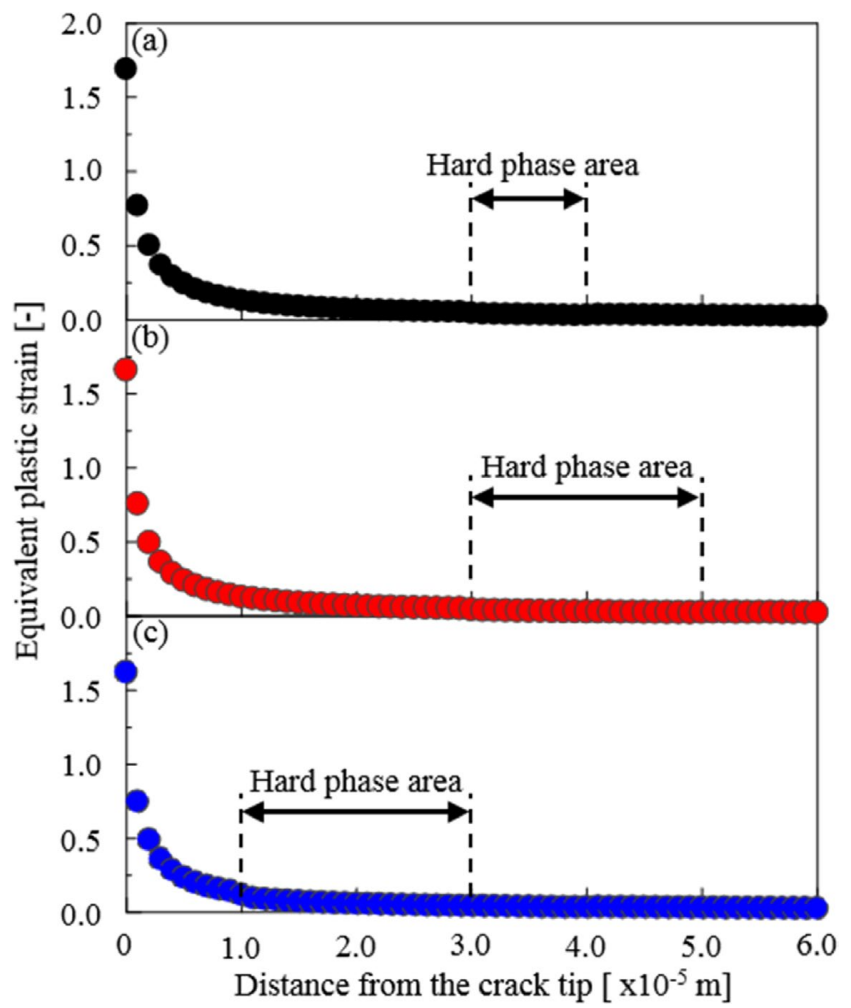

Fig. 8. Equivalent plastic strain from the crack tip. Figures 8(a), $8(\mathrm{~b})$ and $8(\mathrm{c})$ are the results of Model 1, 2 and 3. (Online version in color.)

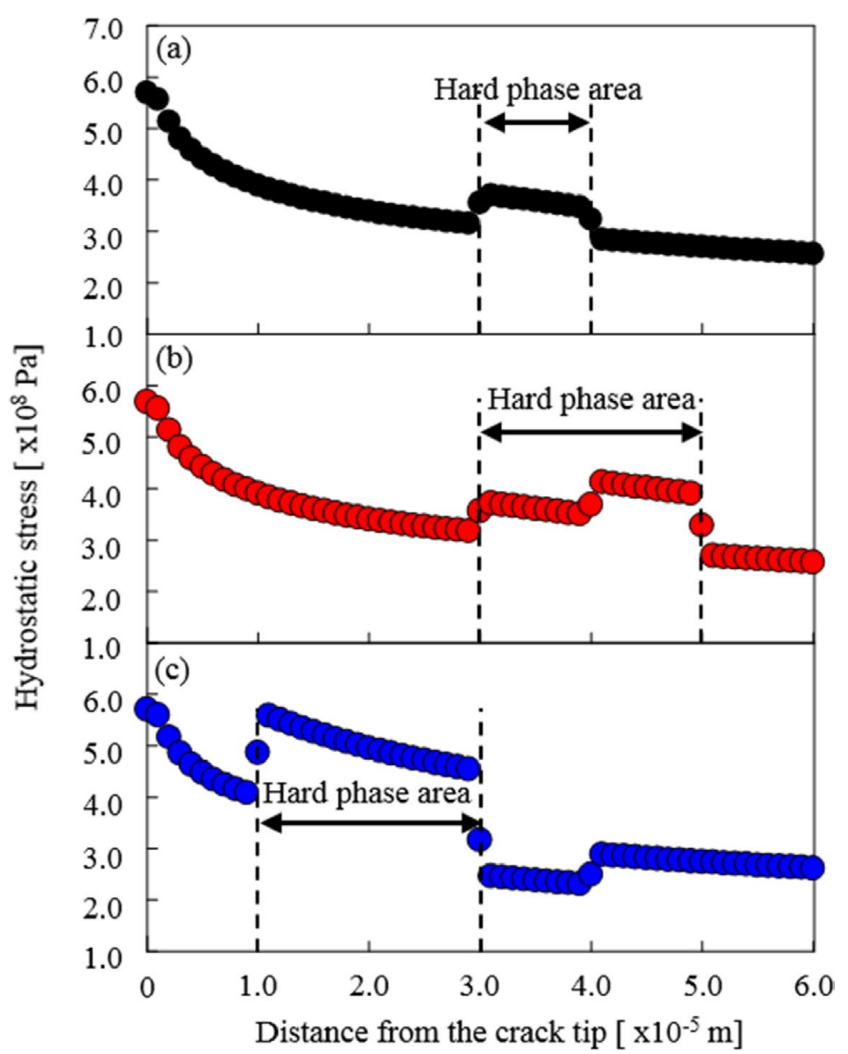

Fig. 9. Hydrostatic stress distribution near the crack tip. Figures 9(a), 9(b) and 9(c) are the results of Model 1, 2 and 3. (Online version in color.)

simulation. As shown in Fig. 9, the hydrostatic stress shows a maximum value at the crack tip and decreases far from the crack. Large values of the hydrostatic stresses were found at the two-phase interface and in the hard phase. The 
maximum values of the hydrostatic stresses at the crack tip $(x=0 \mathrm{~m})$ were $5.69 \times 10^{8}, 5.68 \times 10^{8}$, and $5.70 \times 10^{8}$ $\mathrm{Pa}$ for models 1,2 , and 3, respectively. The hydrostatic stresses at the two-phase interface were $3.55 \times 10^{8} \mathrm{~Pa}(x=$ $\left.3.00 \times 10^{-5} \mathrm{~m}\right), 3.56 \times 10^{8} \mathrm{~Pa}\left(x=3.00 \times 10^{-5} \mathrm{~m}\right)$, and $4.86 \times 10^{8} \mathrm{~Pa}\left(x=1.00 \times 10^{-5} \mathrm{~m}\right)$ for models 1,2 , and 3 , respectively. The hydrostatic stresses near the interface in the soft phase were $3.15 \times 10^{8} \mathrm{~Pa}\left(x=2.90 \times 10^{-5} \mathrm{~m}\right)$, $3.17 \times 10^{8} \mathrm{~Pa}\left(x=2.90 \times 10^{-5} \mathrm{~m}\right)$, and $4.08 \times 10^{8} \mathrm{~Pa}$ $\left(x=9.00 \times 10^{-6} \mathrm{~m}\right)$ for models 1,2 , and 3 , respectively. In summary, the hydrostatic stresses at the two-phase interface were larger than those near the interface in the soft phase. This result indicates that more diffusible hydrogen in the soft phase can be solid-solved. ${ }^{21,27-30)}$

Third, we discuss the influence of the hard phase on the hydrostatic stress gradient. Figure $\mathbf{1 0}$ shows the results of the simulation. When the hydrostatic stress gradient was positive, hydrogen aggregated at the crack tip due to stressinduced diffusion. ${ }^{21,27-30)}$ In models 1 and 2, the hydrostatic stress gradient shows positive values from $x=0 \mathrm{~m}$ to $x=$ $2.80 \times 10^{-5} \mathrm{~m}$ and $2.80 \times 10^{-5} \mathrm{~m}$ with values of $2.07 \times$ $10^{6}$ and $1.92 \times 10^{6} \mathrm{~Pa} / \mu \mathrm{m}$, respectively. In model 3 , the hydrostatic stress gradient had a positive value from $x=0$ $\mathrm{m}$ to $x=8.00 \times 10^{-6} \mathrm{~m}$ with a value of $7.24 \times 10^{6} \mathrm{~Pa} / \mu \mathrm{m}$ at $x=8.00 \times 10^{-6} \mathrm{~m}$.

In the soft phase near the two-phase interface, at $x=$ $2.90 \times 10^{-5} \mathrm{~m}$, the stress gradients were $-4.02 \times 10^{7}$ and $-3.89 \times 10^{7} \mathrm{~Pa} / \mu \mathrm{m}$ in models 1 and 2 , respectively. In model 3 , the hydrostatic stress gradient had a negative value of $-7.85 \times 10^{7} \mathrm{~Pa} / \mu \mathrm{m}$ at $x=9.00 \times 10^{-6} \mathrm{~m}$. The stress gradient was approximately ten times greater than the posi-

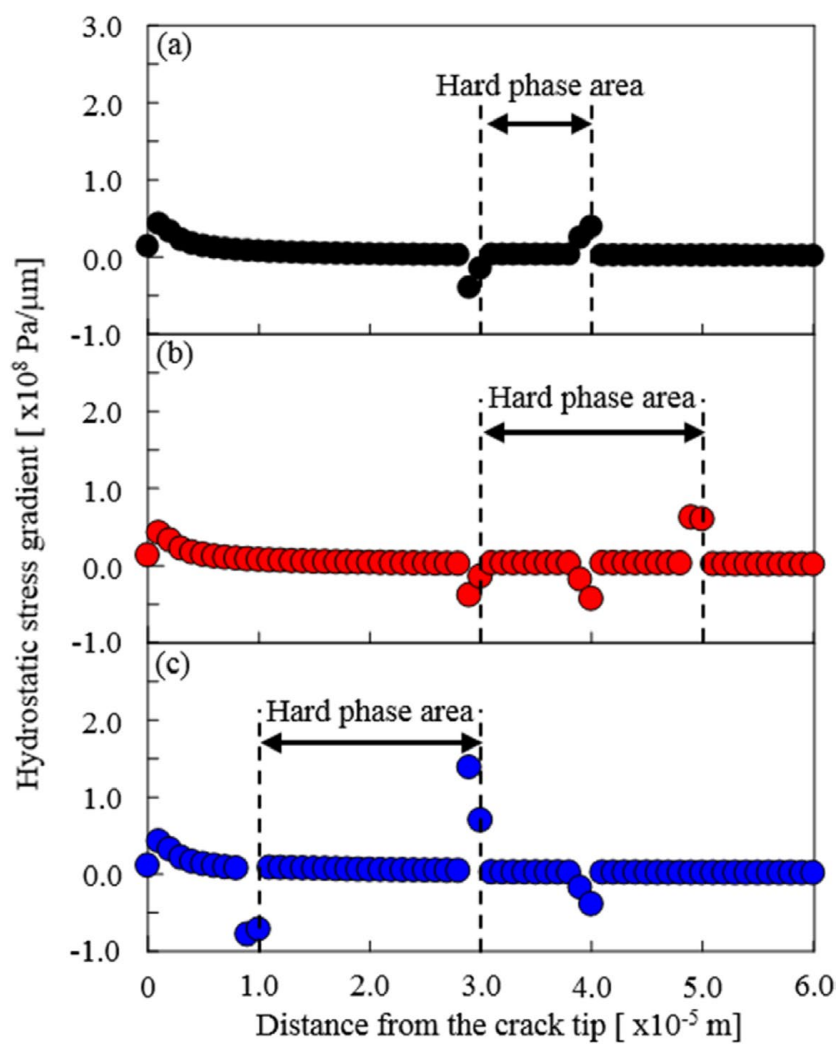

Fig. 10. Hydrostatic stress gradient from the crack tip. Figures 10(a), 10(b) and 10(c) are the results of Model 1, 2 and 3. (Online version in color.) tive stress gradient near the two-phase interface, indicating that the hydrogen diffusion driving force to the interface is large. In summary, the results show that the stress redistribution effect by the hard phase promoted hydrogen diffusion in the soft phase toward the two-phase interface.

These results can be mechanically interpreted as follows. Since the elements of the soft and hard phases at the two-phase interface share nodes, node displacements are necessary to match the two regions. When the soft phase was present in the model, the stress in the hard phase was larger than that of the model with only the hard phase present, because the soft phase elongated further in the vertical direction than the hard phase, and the stress in the soft phase decreased. According to Saint-Venant's principle, stress redistribution in the hard phase produces high stress in the soft phase near the interface and relieves the stress near the crack tip. This interpretation explains the phenomena of increased hydrostatic stress at the interface of the two phases and that of the hydrostatic stress gradient in the soft phase becoming negative, as shown in Figs. 9 and 10.

Here we examine the influence of the hard phase thickness and soft phase space on the fatigue crack propagation behavior under a hydrogen environment, based on the differences in hydrostatic stresses and the stress gradients between the models. First, we consider the influence of the hard phase thickness on hydrogen distribution at the crack tip. The difference of the hydrostatic stress at the interface in model 2 was $0.28 \%$ of that in model 1 . The difference of the hydrostatic stress gradient near the interface in model 2 was $-3.23 \%$ of that in model 1 . Since the hydrogen diffusion rate depends on the hydrogen concentration gradient and the hydrostatic stress gradient, when the hydrogen concentration in the material is uniform, the hydrogen diffusion rate to the two-phase interface decreased by $3.23 \%$. These results show that when the hydrogen concentration in the material was uniform, the time required to concentrate hydrogen on the two-phase interface increased instead of increasing the hydrogen solid solution concentration at the two-phase interface.

Next, we consider the effect of the soft phase interval. Comparing models 2 and 3, the difference between the hydrostatic stresses was $36.5 \%$ of the hydrostatic stress of model 2 at the two-phase interface. Comparing the hydrostatic stresses of models 1, 2, and 3, the decrease in the soft phase interval promoted the increase of dissolved hydrogen more than the hard phase thickness. Comparing models 2 and 3, the difference in the hydrostatic stress gradient near the two-phase interface was $102 \%$. In the other words, when the amount of hydrogen from the crack tip to the two-phase interface was constant, the hydrogen diffusion rate toward the interface doubled. These results show that by decreasing the soft phase interval, the solid solution hydrogen concentration at the two-phase interface increased and the time required for hydrogen enrichment to the two-phase interface decreased.

In summary, the FEM simulations produced the following results: 1) The hard phase thickness and the soft phase interval had little effect on the plastic strain at the crack tip. 2) The hydrostatic stress was maximum at the crack tip. 3) The hydrostatic stress gradient promoted hydrogen diffusion to the interface near the two-phase interface. 4) The 
increase of the hard phase thickness increased the hydrogen solid solution concentration at the two-phase interface and increased the time required to concentrate hydrogen on the two-phase interface. 5) The decrease of the soft phase interval increased the hydrogen solid solution concentration at the two-phase interface and decreased the time required for hydrogen enrichment. The promotion of hydrogen enrichment shows that the localized hydrogen due to the maximum hydrostatic stress at the crack tip was relaxed by diffusion to the two-phase interface. According to the results of models 1 and 3 simulated materials A and B, material B better mitigated hydrogen enrichment at the crack tip.

Factors that are essential in the hydrogen promotion of fatigue crack propagation are the local hydrogen concentration and local plastic strain at the crack tip. ${ }^{19,22)}$ Based on the simulation results and result 4 ) of the surface observations, the increase of the thickness and the decreased soft phase interval promotes stress redistribution, resulting in the relaxation of the local hydrogen concentration and the suppression of hydrogen supported fatigue crack propagation.

\subsection{Stress Redistribution on an Internal Crack}

In this section we discuss the influence of the stress field and the plastic strain at the internal crack tip using an analytical model of the plane strain state. We modify model 3 from the plane stress state to the plane strain state, and henceforth refer to it as model 4. Figure 11 shows the model results. As shown in Fig. 11(a), the plastic strain at the crack tip decreased to 0.39 , which is about 0.24 times that of the plane stress state. At $4 \mu \mathrm{m}$ from the crack tip, the plastic strain became constant. The plastic region with a high plastic strain of 0.02 decreased by a factor of 10 compared to that of the plane stress state. As shown in Fig. 11(b), the maximum hydrostatic stress at the crack tip was $1.25 \times 10^{10}$ $\mathrm{Pa}$, which is approximately 22 times larger compared to that of the plane stress state. This result indicates that the maximum solid solution hydrogen concentration was significant.

The hydrostatic stress gradient up to the interface of the two phases, as shown in Fig. 11(c), had a significantly larger value than that of the plane stress state, and it promoted the localized concentration of hydrogen at the crack tip. Local hydrogen concentration at the crack tip is vital for hydrogen-promoted fatigue crack propagation. ${ }^{19,22)}$ From the viewpoint of the hydrogen concentration, the suppression of the fatigue crack propagation by stress redistribution was expected to be lower in the plane strain condition mechanically.

The decrease in stress redistribution under the plane strain condition is interpreted as follows. An equivalent stress, $\sigma_{\text {eq }}$, is expressed by Eq. (1), where $\sigma_{\mathrm{ii}}$ is the normal stress to the $i$ plane. A shear stress, $\tau_{\mathrm{ij}}$, is directed in the $j$ direction for the $i$ plane.

$$
\begin{aligned}
& \sigma_{e q}= \\
& \frac{1}{\sqrt{2}}\left[\left(\sigma_{x}-\sigma_{y}\right)^{2}-\left(\sigma_{y}-\sigma_{z}\right)^{2}-\left(\sigma_{z}-\sigma_{x}\right)^{2}+6\left(\tau_{x y}^{2}+\tau_{y z}^{2}+\tau_{z x}^{2}\right)\right]^{\frac{1}{2}}
\end{aligned}
$$

In the plane strain state, the element at the crack tip was constrained in the depth direction. As the stress in the model depth direction increased, so did the stress triaxiality.
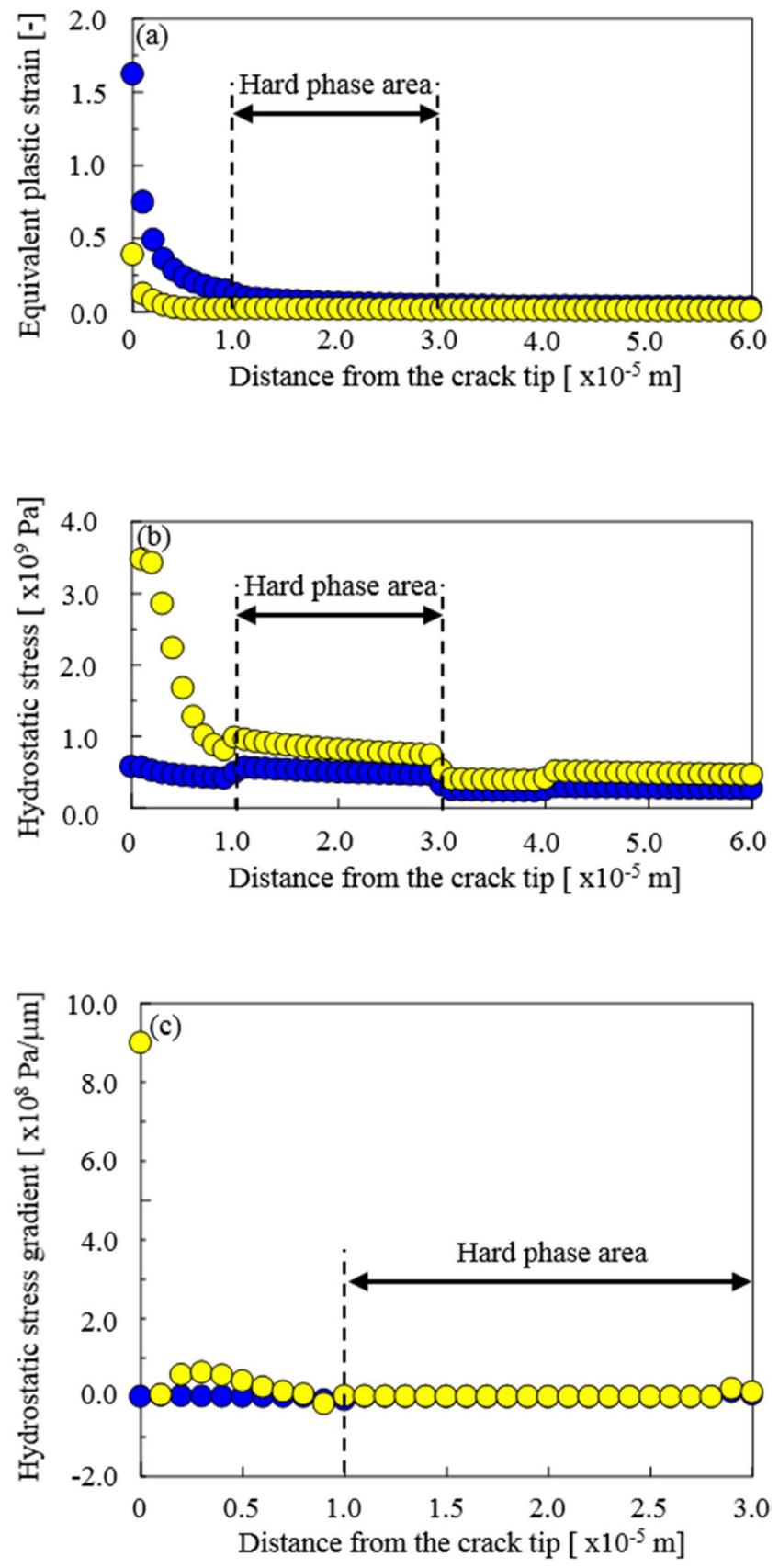

Fig. 11. Comparison between the results of plane stress and strain condition. (a) Equivalent plastic strain. (b) Hydrostatic stress. (c) Hydrostatic stress gradient. Blue and yellow marks are results of plane stress and strain condition, respectively. (Online version in color.)

Therefore, the equivalent stress decreased, indicating that the elongation and the strain of the soft phase decreased. Then, the vertical elongation-promoting effect of the soft phase decreased, resulting in the reduction of the elongation of the hard phase. In other words, stress redistribution could not be observed because the difference in deformation due to the crack tip stress field was less than the difference in the two-phase initial yield strength.

Hydrogen diffusion is influenced by the lattice diffusion coefficient, diffusible hydrogen concentration, time, temperature, hydrostatic stress gradient, number of trap sites related to plastic strain amount, etc. ${ }^{22,29,31)}$ In the case of plane strain conditions, as the numerical analysis results show, the hydrostatic stress is high, and the hydrostatic 
stress gradient is large, inducing hydrogen localization at the crack tip. Thus, in the plane strain state, a significant difference in hardness between the two phases is required mechanically for suppression of hydrogen-assisted fatigue crack propagation. A change in local hydrogen content due to stress redistribution remains as a future study.

\section{Conclusion}

The present study aimed to clarify the influence of stress redistribution on hydrogen-accelerated fatigue crack propagation. We conducted in situ crack observations under plane bending tests, fracture surface analyses, and FEM analyses. The results are summarized as follows:

(1) The in situ observations revealed that the crack propagation rate decreased in the soft phase as the hard phase fraction increased. The fracture analysis showed that the brittle fracture rate in the soft phase decreased as the hard phase fraction increased. These results indicate that an increase in the hard phase fraction suppressed hydrogenpromoted crack propagation.

(2) Numerical analysis demonstrated that the hard phase suppressed hydrogen localization at the crack tip in the soft phase by stress redistribution.

(3) When the plane strain state is dominant, a substantial hardness difference between the two phases is mechanically necessary to suppress hydrogen-promoted crack propagation.

\section{REFERENCES}

1) J. P. Hirth: Metall. Trans. A, 11 (1980), 861

2) M. Koyama, E. Akiyama, K. Tsuzaki and D. Raabe: Acta Mater., 61 (2013), 4607.

3) M. Koyama, C. C. Tasan, E. Akiyama, K. Tsuzaki and D. Raabe: Acta Mater., 70 (2014), 174.

4) D. Sasaki, M. Koyama and H. Noguchi: Philos. Mag. Lett., 95 (2015),
260 .

5) M. Wang, E. Akiyama and K. Tsuzaki: Scr. Mater., 52 (2005), 403.

6) T. Ogawa, M. Koyama and H. Noguchi: ISIJ Int. 56 (2016), 1656.

7) H. Kobayashi, T. Yamada, H. Kobayashi and S. Matsuoka: J. High Press. Gas Saf. Inst. Jpn., 53 (2016), 5 (in Japanese).

8) Y. Wada and H. Arashima: JSW Tech. Rev., 65 (2014), 36.

9) H. Hirukawa, Y. Furuya and M. Hayakawa: Tetsu-to-Hagané, 93 (2007), 600 (in Japanese).

10) Y. Yamashita and Y. Murakami: Int. J. Fatigue, 93 (2016), 406.

11) E. J. Song, S. W. Baek, S. H. Nahm and U. B. Baek: Int. J. Hydrog. Energy, 42 (2017), 8075.

12) Y. Onishi, M. Koyama, D. Sasaki and H. Noguchi: ISIJ Int., 56 (2016), 855.

13) H. K. Birnbaum and P. Sofronis: Mater. Sci. Eng. A, 176 (1994), 191.

14) I. M. Robertson, P. Sofronis, A. Nagao, M. Martin, S. Wang, D. Gross and K. Nygren: Metall. Mater. Trans. A, 46 (2015), 2323.

15) H. Nishikawa, Y. Oda and H. Noguchi: J. Solid Mech. Mater. Eng., 5 (2011), 263

16) D. Lee, H. Nishikawa, Y. Oda and H. Noguchi: Int. J. Fract., 179 (2012), 147.

17) M. Yoshikawa, N. Tsutsumi, S. Matsuoka and Y. Murakami: Trans. Jpn. Soc. Mech. Eng. A, 76 (2010), 908 (in Japanese).

18) Y. Takahashi, M. Tanaka, K. Higashida, K. Yamaguchi and H. Noguchi: Acta Mater., 58 (2010), 1972.

19) H. Nishikawa, Y. Oda, Y. Takahashi and H. Noguchi: J. Solid Mech. Mater. Eng., 5 (2011), 179.

20) Y. Takahashi, H. Nishikawa, Y. Oda and H. Noguchi: Mater. Lett., 64 (2010), 2416

21) M. Nagumo: Mater. Sci. Technol., 20 (2004), 940.

22) D. Sasaki, M. Koyama, K. Higashida, K. Tsuzaki and H. Noguchi: Int. J. Hydrog. Energy, 40 (2015), 9825.

23) J. Toribio, M. Lorenzo, D. Vergara and L. Aguado: Constr. Build. Mater., 114 (2016), 317.

24) J. C. Kim, S. K. Cheong and H. Noguchi: Int. J. Fatigue, 55 (2013), 147.

25) R. A. Gonzaga, P. M. Landa, A. Perez and P. Villanueva: J. Achiev. Mater. Manuf. Eng., 33 (2009), 150.

26) S. Hamano, T. Shimizu and T. Noda: Denki Seiko, 77 (2006), 107 (in Japanese).

27) R. Mizuno, H. Matsuda, Y. Funagawa and Y. Tanaka: Tetsu-toHagané, 96 (2010), 414 (in Japanese)

28) R. M. McMeeking: J. Mech. Phys. Solids, 25 (1977), 357.

29) P. Sofronis and R. M. McMeeking: J. Mech. Phys. Solids, 37 (1989), 317.

30) A. H. M. Krom, R. W. J. Koers and A. Bakker: J. Mech. Phys. Solids, 47 (1999), 971.

31) H. Kotake, R. Matsumoto, S. Taketomi and N. Miyazaki: Int. J. Press. Vessel. Pip., 85 (2008), 540 